\title{
Evaluation of in vitro Antioxidant Potential of Amaranthus caudatus L. Grown in Kashmir Region
}

\author{
Asiya Ramzan', Inayatullah Tahir², Reiaz UI Rehman 1,*
}

\begin{abstract}
Asiya Ramzan ${ }^{1}$ Inayatullah Tahir ${ }^{2}$ Reiaz UI Rehman ${ }^{1, *}$

'Department of Bioresources, University of Kashmir, Srinagar, Jammu and Kashmir-190006, INDIA.

${ }^{2}$ Department of Botany, University of Kashmir, Srinagar, Jammu and Kashmir-190006, INDIA.
\end{abstract}

\section{Correspondence: \\ Dr. Reiaz UI Rehman}

Department of Bioresources University of Kashmir, SrinagarJammu and Kashmir-190006, INDIA.

Phone no: +91-9796546222

Email: rreiazbiores@gmail.com

bhatasiya329@yahoo.in

\section{History \\ - Submission Date: 30-03-2018; \\ - Review completed: 23-05-2018; \\ - Accepted Date: 23-07-2018.}

DOI : 10.5530/pj.2018.6.190

Article Available online http://www.phcogj.com/v10/i6

\section{Copyright}

(c) 2018 Phcog.Net This is an open-access article distributed under the terms of the Creative Commons Attribution 4.0 International license.

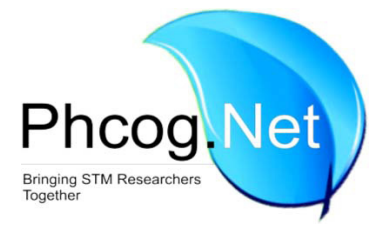

\begin{abstract}
Background: Plants have a well-developed defensive machinery for minimizing the reactive oxygen species (ROS) associated damages in the form of enzymatic and non-enzymatic antioxidants. The in-vitro mechanism of antioxidant action of plant extracts may involve direct inhibition of the ROS generation or ROS scavenging. The antioxidant activity of the extracts may be due to active constituents alone or the combination of constituents. However, the amount of constituents are known to vary according to the change in environment. Method: In our study, antioxidant activity of Amaranthus caudatus L. from two different sites (elevation sites) was investigated at three stages, (vegetative, pre flowering and post flowering) using ethanolic extract (EtOH). Result: The phenolic and flavonoid content increased at all stages from site 1 to site 2. The total reducing power, Ferrous reducing antioxidative power (FRAP), diphenyl picryl hydrazine (DPPH) radical scavenging assay, superoxide dismutase scavenging (SOD) assay and hydrogen peroxide $\left(\mathrm{H}_{2} \mathrm{O}_{2}\right)$ scavenging activity increased from site 1 to site 2 at all the three stages. Conclusion: The results reveal that the altitude and the growth stage have a significant effect on antioxidative potential of Amaranthus.
\end{abstract}

Key words: Amaranthus, Ethanolic extract, Phenolics, Hydrogen peroxide, Superoxide dismutase, Reactive oxygen species.

\section{INTRODUCTION}

Reactive oxygen species (ROS) are manufactured by living beings during metabolic activities of cell and are regulated by various machineries viz. enzymatic and non-enzymatic protective mechanisms. ROS are unstable which react with various biomolecules (DNA, lipids and proteins), modifying them structurally as well as functionally. The production of ROS is known to increase by various factors like environmental pollutants, hazardous chemicals, food adulterants, smoking and thus disturb the balance between the ROS production and ROS quenching which leads to oxidative stress. ${ }^{1,2}$ Due to the inadequacy of these antioxidative components (enzymatic and non-enzymatic components) in our body, we need to incorporate the plants or their products in our diets that possess good antioxidative activities so that the collective effect of oxidative stress is curtailed. Although there are choices of synthetic antioxidants, yet their use has been limited due their health related issues. Thus, various plant species or their products are increasingly investigated by researchers for antioxidant activity ${ }^{3}$ to protect cells from oxidative stress that accelerates ageing, Alzheimer's disease, cancer and coronary heart disease. ${ }^{4-6}$ The protective nature of plants and their products is because of the diverse chemical constituents present in them such as enzymes, proteins, vita- mins; ${ }^{7}$ carotenoids; ${ }^{8}$ flavonoids ${ }^{9}$ and phenolic compounds. ${ }^{10}$ However, the medicinal properties are restricted to about two third of the total plant species globally ${ }^{11}$ and thus quest for a medicinal plant is increasing. Amaranthus caudatus, belonging to family Amaranthaceae, is rare multifunctional crop grown in both temperate and tropical regions of world as vegetable, grains and coloring agent as well as for ornamental purposes. ${ }^{12}$ The plant grows in wide range of climatic conditions with minimum external inputs and shows tolerance towards heat, drought, diseases and pests. ${ }^{13}$ The plant is accredited with medicinal value as it possesses hepatoprotective,$^{14}$ antihelminthic, ${ }^{15}$ antinociceptive and antipyretic ${ }^{16}$ as well as antidepressant activity ${ }^{17}$ and anti-hyperlipidemic activity. ${ }^{18,19}$ The presence of different compounds in Amaranthus caudatus makes it a potential plant species for studying the antioxidant potential. ${ }^{20}$ The expression of compounds possessing antioxidant activity is influenced by the different environmental conditions. The concentration of active substances show positive correlation with increasing altitude, as it is associated with many ecological factors like temperature, humidity, duration of snow cover, length of vegetative period, soil composition and $\mathrm{pH}^{21}$ Such ecological factors 
control the production of secondary metabolites. Plants grown at high altitude may bring change in biochemical components to resist the stress conditions. ${ }^{22}$ Besides the altitudinal difference the bioactive components of plants show variation at different growth stages ${ }^{22}$ and thus the present study has been undertaken to check the in vitro antioxidative potential of Amaranthus caudatus grown in Kashmir region at two different sites at various stages of plant growth.

\section{MATERIALS AND METHODS}

\section{Collection of plant material}

The seeds were collected from SKUAST-K (Sheri Kashmir University of Agricultural science and Technology-Kashmir) and were grown at two places viz. Nagbal (1581amsl, Site 1) and Wangath (2100 amsl, Site 2) (district Ganderbal). The leaves were collected at three different stages viz. vegetative stage (Stage I) i.e., after the $5^{\text {th }}$ week of sowing, pre flowering (Stage II) i.e., after the $10^{\text {th }}$ week of sowing and post flowering stage i.e., after the $17^{\text {th }}$ week of sowing. Leaves were shade dried, powdered and stored in air tight bags until used.

\section{Extraction of plant material}

$5 \mathrm{~g}$ of dried powdered leaf material was extracted with $50 \mathrm{ml}$ of $80 \%$ ethanol using a shaker for $24 \mathrm{hrs}$ at room temperature. The mixtures were filtered and the supernatant was kept in air tight tubes and was properly labelled and kept at $4^{\circ} \mathrm{C}$ until further use. The total phenolic content, total flavonoid content was estimated and antioxidant activity assays were performed using following methods.

\section{Total phenolic content determination}

Total phenolic content in leaf material was determined by using FolinCiocalteau reagent (FC) method $^{23}$ and gallic acid was used as standard phenolic compound. The absorbance was measured at $650 \mathrm{~nm}$ using spectrophotometer (Shimadzu, Japan) against a blank reagent. The total soluble phenolic content in leaf extracts was expressed in $\mathrm{mg} / \mathrm{g}$ of gallic acid equivalents.

\section{Total flavonoids determination}

The total flavonoids were determined by Aluminium chloride $\left(\mathrm{AlCl}_{3}\right)$ colorimetric method ${ }^{24}$ and absorbance was recorded at $415 \mathrm{~nm}$. The total flavonoid content was estimated using rutin as a standard from which unknown concentration of the sample was estimated. The flavonoid content was expressed in $\mathrm{mg} / \mathrm{g}$ of dry rutin equivalents.

\section{Total Reducing Power}

The total reducing power was assayed by the method of Yen and Duh, $(1993)^{25}$ and the absorbance was measured at $700 \mathrm{~nm}$. The increase in absorbance indicated an increase in reducing power.

\section{Ferrous Reducing Antioxidant Power Assay (FRAP)}

The antioxidant potential was assayed using the method of Benzie and Strain, (1996) ${ }^{26}$ with little modification. An aliquot of $10-50 \mu l$ extracts was mixed with $2.9 \mathrm{ml}$ of FRAP reagent and kept in dark for $10 \mathrm{~min}$. The bluish coloured product so formed was read at $593 \mathrm{~nm}$. Here ferrous sulphate was used as standard. Results obtained were expressed in $\mu \mathrm{MFe}$ (II)/g.

\section{1,1 diphenyl 2- picryl hydrazine (DPPH) Percentage Inhibition Activity}

The antioxidative scavenging activity was assayed by using a stable free radical 1, 1 diphenyl 2- picryl hydrazine (DPPH) method. ${ }^{27}$ The reaction mixture was incubated in dark for $10 \mathrm{~min}$ and the absorbance was read at $517 \mathrm{~nm}$. The percentage inhibition activity was calculated by using formula.

Percentage inhibition $=\mathbf{A}_{\text {Control }}-\mathbf{A}_{\text {Sample } /} \mathbf{A}_{\text {Control }} \times \mathbf{1 0 0}$

\section{Superoxide Radical Scavenging Activity}

Superoxide anions were measured using the method of Beauchamp and Fridovich, (1971). ${ }^{28}$ In this assay, PMS and riboflavin generate the superoxide radicals. These superoxide radicals are in turn assayed by the reduction of NBT with the formation of purple colour. The percentage inhibition of superoxide anion generation was estimated using formula. Percentage inhibition $=\mathbf{A}_{\text {Control }}-\mathbf{A}_{\text {Sample } /} \mathbf{A}_{\text {Control }} \times \mathbf{1 0 0}$

\section{Hydrogen peroxide scavenging activity}

Hydrogen peroxide scavenging activity was assayed using $\mathrm{H}_{2} \mathrm{O}_{2}$ reagent. $^{29}$ The reaction mixture was incubated at room temperature for $10 \mathrm{~min}$ and the absorbance was measured at $230 \mathrm{~nm}$ against blank where no $\mathrm{H}_{2} \mathrm{O}_{2}$ was added.

Percentage inhibition $=\mathbf{A}_{\text {Control }}-\mathbf{A}_{\text {Sample } /} \mathbf{A}_{\text {Control }} \times \mathbf{1 0 0}$

\section{Statistical analysis}

The experimental data were expressed as mean \pm standard deviation (SD) of three replicates. The results were analyzed by using analysis of variance (ANOVA) and the antioxidant potential of various assays was determined as $\mathrm{IC}_{50}$ values by using Graph pad prism 5-software. Results were regarded as statistically significant at $p \leq 0.05$.

\section{RESULTS AND DISCUSSION}

The antioxidant potential of Amaranthus caudatus L. was checked by the in vitro antioxidant assays viz. total reducing power, DPPH radical scavenging activity, superoxide radical scavenging activity and ferrous reducing antioxidant power. Besides, the total phenolic and total flavonoid content were also estimated in the plant extracts.

\section{Total Phenolic Content}

Amaranthus caudatus L. plants were grown at two different sites and the total phenolic content was monitored in the leaves collected at various stages of growth. In this method, phenols get oxidized by a molybdotungstate reagent (FC reagent) which gives blue coloured complex. The phenolic content at site 1 and 2 was $1.250 \pm .066 \mathrm{mg}$ per gram and 3.340 $\pm .05 \mathrm{mg} / \mathrm{g} \mathrm{GAE}$, stage I; $1.193 \pm .09$ and $5.37 \pm .034 \mathrm{mg} / \mathrm{g}$ GAE, stage II and $1.41 \pm .07$ and $7.58 \pm 0.43 \mathrm{mg} / \mathrm{g}$ GAE, stage III (Figure 1A). The total phenolic content in Amaranthus caudatus increased from vegetative to post-flowering stages at both sites. However, the phenolic content was significantly higher at site 2 with 1.67, 3.5 and 4.4 fold increase at vegetative, pre-flowering and post-flowering stages respectively. The phenolics present in the plants contribute to their antioxidant activity due to their typical structure that induces the property of electron donating capacity, the chain breaking function of free radicals and termination of Fenton reaction. ${ }^{30}$ It is clearly illustrated that plants grown at low altitude (Site 1) exhibit low phenolic content than those grown at high attitude (Site 2) at all the three stages. It was also spotted that ethanolic extracts showed maximum activity than other extracts used during this study. The results were supported by Enujiugha et al. $(2014)^{31}$ who examined the phenolics in ethanolic extracts from leaves of Amaranthus caudatus. After comparing the three stages, it was revealed that stage III showed highest phenolic content at both the sites followed by the stage I and the least phenolic content was observed in stage II. As per the earlier reports ${ }^{32,33}$ the phenolic content increased with the maturity of plant and was present in less quantity in newly opened leaves. The low phenolic content in stage II at both the sites indicates that besides altitudinal variations, this might be due to seasonal variation that renders profound effect on antioxidant 
activity. As per Shahid and Bhanger, $(2006)^{34}$ during hotter seasons the phenolic content decreases as was also observed in our study during the stage II.

\section{Total Flavonoid Content}

Determination of total flavonoids using Aluminium Chloride $\left(\mathrm{AlCl}_{3}\right)$ method is based upon the formation of stable complex between $\mathrm{AlCl}_{3}$ and hydroxyl group or ketonic group of flavones and flavonoids present within extract. Here rutin was used as a standard compound. The flavonoid content at site 1 and site 2 was $0.95 \pm 0.031$ and $1.63 \pm 0.17$ $\mathrm{mg} / \mathrm{g} \mathrm{RE}$, stage $10.47 \pm 0.026$ and $0.83 \pm 0.019 \mathrm{mg} / \mathrm{g} \mathrm{RE}$, stage II and $0.929 \pm .007$ and $1.140 \pm .200 \mathrm{mg} / \mathrm{g}$ RE respectively (Figure 1B). The total flavonoid content varied significantly with the developmental stages (I, II and III) at both sites. Sites I when compared to their respective stages at site 2 , attaining a decline of $0.715,0.772$ and 0.212 respectively at three stages. The flowering content increased at post flowering stage by $2.27 \%$ at stage 1 and $30.09 \%$ present at stage 2 when compared to vegetative stage. The pre-flowering stage showed sharp decline when compared to other two developmental stages. The flavonoid content increased significantly from vegetative to post flowering stage. Flavonoids, the polyphenolic compounds, ubiquitous in nature have awakened interest because of beneficial effects on humans and possess antiviral, antiallergic, antiinflammatory, antitumor, anti-neoplastic, antiviral and vasodilatory and antioxidant activities. ${ }^{35,36}$ The antioxidant and free radical scavenging activity of these compounds can be attributed to their molecular structure as the position of hydroxyl groups and other properties. The present study in Amaranthus caudatus L. revealed that the total flavonoid content increased with the increase in altitude at all the three stages, however, site 2 exhibited higher flavonoid content compared to site 1 . In general, highest flavonoid content was observed at stage I in both the cases followed by stage III and lowest at stage II. The flavonoid content in our study was far better than the values reported in same plant by Akubugwo et al. (2008) $)^{37}$ that ranged between $0.38-0.83 \mathrm{mg} / 100 \mathrm{~g}$ but were less than $28.19-42.84 \mathrm{mg} / \mathrm{g}^{38}$ and $69.67 \mathrm{mg} / \mathrm{g} .{ }^{39}$ The high phenolic and flavonoid content present in plants and their products result in their high antioxidant activities. ${ }^{40}$

\section{Total Reducing Power}

In this assay potassium ferricyanide $\left[\mathrm{K}_{3} \mathrm{Fe}(\mathrm{CN})_{6}\right]$ reacts with ferric chloride $\left(\mathrm{FeCl}_{3}\right)$ in presence of extract to give potassium ferrocyanate $\left[\mathrm{K}_{4}\right.$ $\left.\mathrm{Fe}(\mathrm{CN})_{6}\right]$ and ferrous chloride $\left(\mathrm{FeCl}_{2}\right)$. This complex shows maximum absorbance at $700 \mathrm{~nm}$ and oxidation state changes from $\mathrm{Fe}^{3+}$ (ferric cyanate complex) to $\mathrm{Fe}^{2+}$ (ferrous form). Increase in OD indicates increase in antioxidative activity. Thus reducing power indicates the electron donating capacity and antioxidative activity and hence colour changes from yellow to green or prussian blue. The total reducing power at site 1 and 2 were $0.91 \pm 0.007 \mathrm{~nm}$ and $1.56 \pm 0.004 \mathrm{~nm}$, stage I; $0.35 \pm 0.03$ $\mathrm{nm}$ and $1.32 \pm 0.012 \mathrm{~nm}$ stage II and $1.17 \pm 0.005 \mathrm{~nm}$ and $1.38 \pm 0.009$ $\mathrm{nm}$, stage III (Figure 2A). There was an increment from site 1 to site 2 by 0.71 fold, 2.82 fold and 0.18 fold at vegetative, pre-flowering and post flowering stages. However, comparing different developmental stage, the pre-flowering stage showed decline of 0.61 fold at site 1 and 0.15 fold at site 2 when compared to vegetative stage. Furthermore, the total reducing power at post flowering stage increased by 0.28 fold at site 1 and decreased by 0.11 fold from vegetative to post flowering stage. The reducing power is correlated to the antioxidant activity as is apparent in the in-vitro system where they donated electrons. ${ }^{41}$ It was also observed that with the increase in the altitude the total reducing power increased i.e., total reducing power was high at site 2 compared to site 1 . After comparing three stages, it was also observed that total reducing power was higher in case of stage I. However, the total reducing power decreased at stage II and then exhibiting an increase at stage III. This again indicated
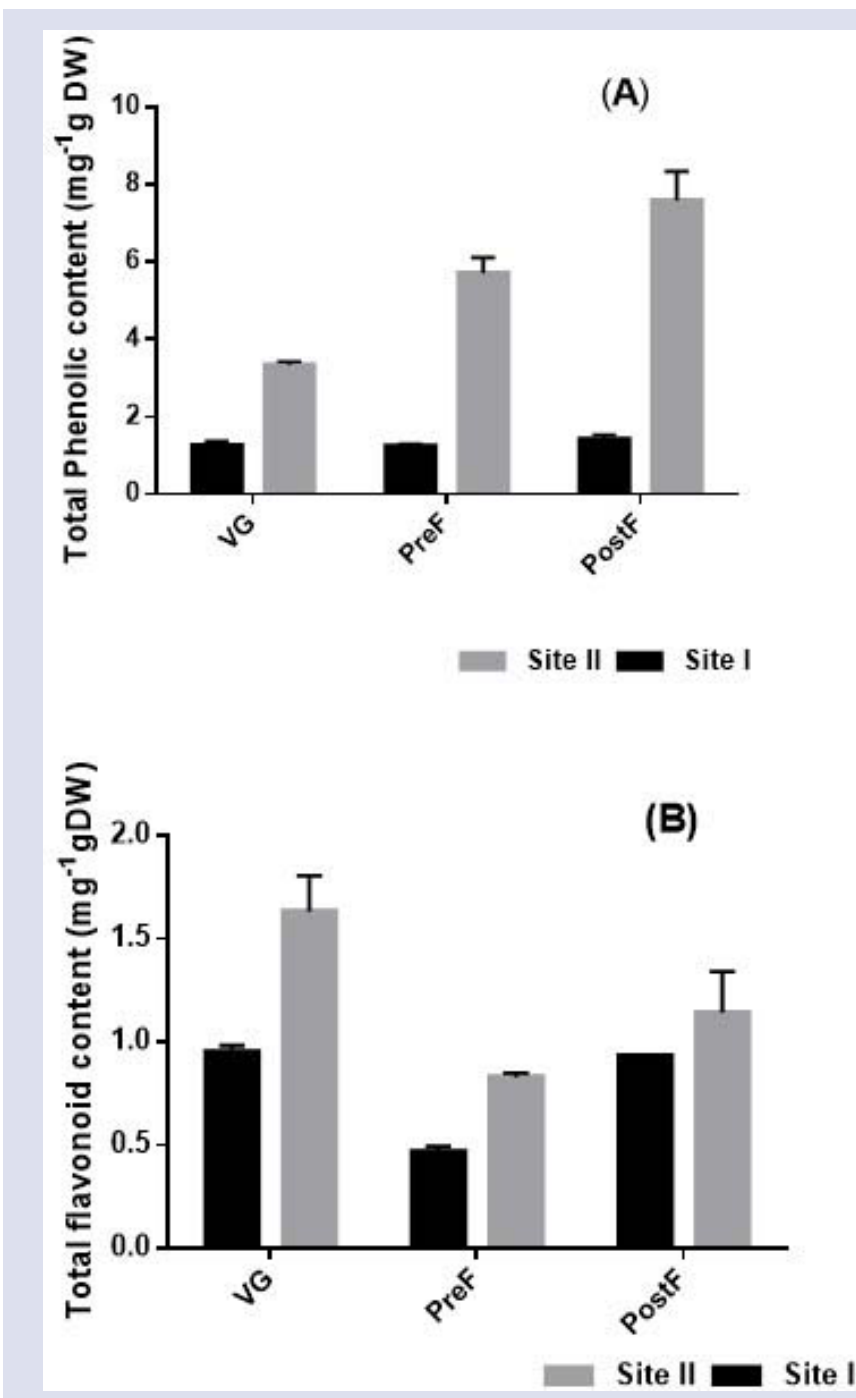

Figure 1: Total phenolic content (A) and flavonoid content (B) in ethanolic leaf extract of Amaranthus caudatus L. grown at two different sites.

that besides the altitudinal variation, seasonal effect is clearly playing an important role as the less activity of total reducing power was observed in stage II. However, the inherent resource allocation pattern of the plant can also be a decisive factor in the overall physiological and biochemical development of the plant. ${ }^{42}$

\section{Ferrous Reducing Antioxidative Power (FRAP)}

The ferrous reducing antioxidant power assay is used to observe the ability of extract to reduce ferric ions. In FRAP assay complex between 2, 4, 6-tri-pyridyl-s-triazine (TPTZ) and Ferric chloride $\left(\mathrm{FeCl}_{3}\right)$ is formed which is then reduced to ferrous (Fe II-TPTZ) complex which is strongly absorbed at $593 \mathrm{~nm}$. The reaction is $\mathrm{pH}$ dependant and reaction proceeds only in acidic medium ( $\mathrm{pH}$ 3.6). In stage I the FRAP activity was $36.49 \pm 1.29 \mu \mathrm{MFe}(\mathrm{II}) / \mathrm{g}, 65 \pm 0.51$, stage I; $34.96 \pm 0.86 \mu \mathrm{MFe}(\mathrm{II}) / \mathrm{g}$ and $38.2 \pm .20 \mu \mathrm{MFe}(\mathrm{II}) / \mathrm{g}$, stage II and $42.06 \pm 0.89 \mu \mathrm{MFe}(\mathrm{II}) / \mathrm{g}$ and 43.99 $\pm 1.95 \mu \mathrm{MFe}$ (II)/g stage III (Figure $2 \mathrm{~B}$ ). The FRAP activity increased significantly from Site 1 to site 2 at all the three stages of development i.e. the FRAP activity increased by $78.39 \%, 9.27 \%$ and $4.59 \%$ at vegetative, pre-flowering and post flowering stage respectively. However, the FRAP activity decreased from vegetative to pre-flowering stage by $4.19 \%$ and $41.20 \%$ and it increased from pre-flowering to post flowering stage by $20.29 \%$ and $15.14 \%$ from site 1 and 2 respectively. The ferrous 
reducing antioxidant power (FRAP) assay method offers the quantitative estimation of Fe II-TPTZ that are formed as products. In this assay ferric 2,4,6-tripyridyl-s-triazine are utilized and changed into its ferrous form (intense blue colour) by the plant extracts possessing antioxidant
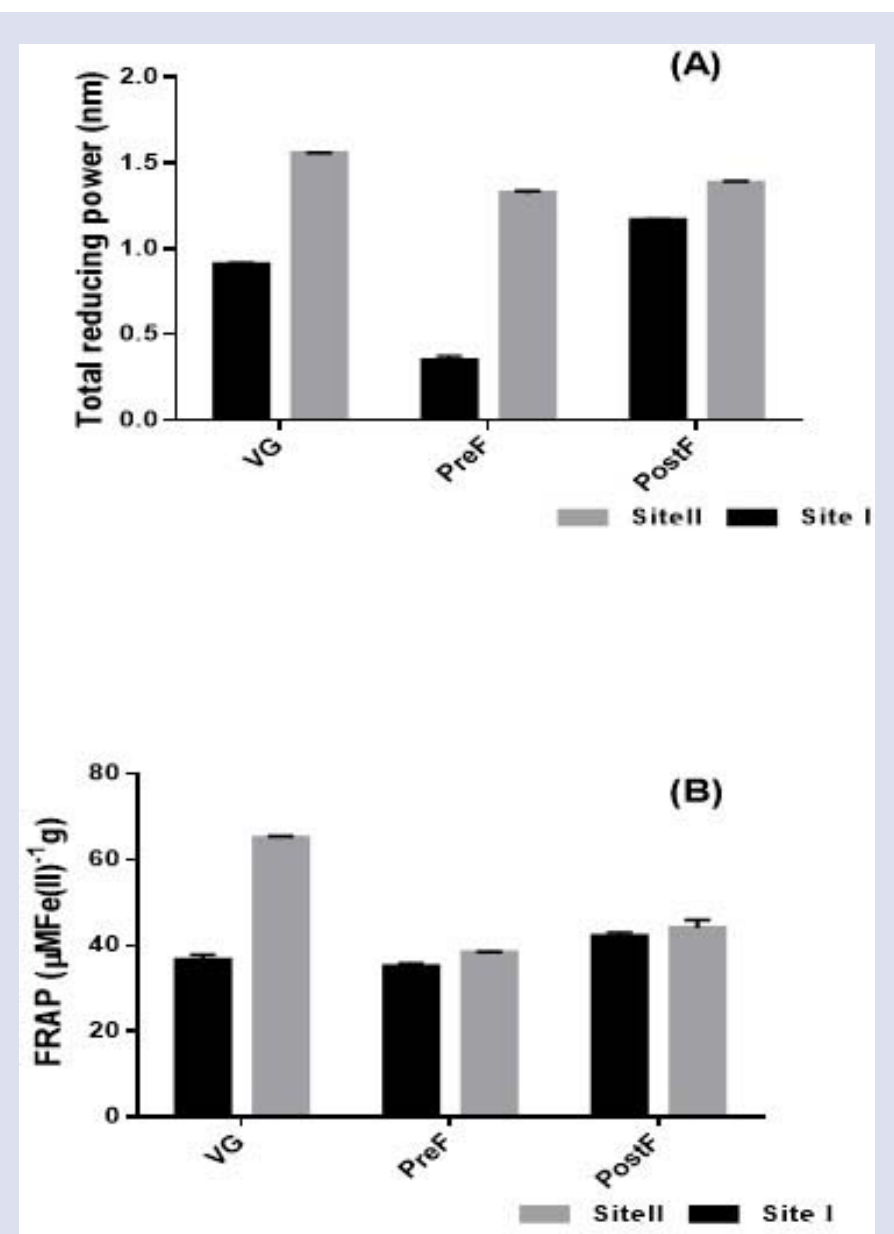

Figure 2: Total Reducing power (A) and FRAP activity (B) in ethanolic leaf extract of Amaranthus caudatus L. grown at two different sites.

capability. The results clearly depict that plants grown at site 2 had better activity and similar to earlier assays vegetative stage was better than preflowering stage indicating that activity is also affected by agroclimatic zonation and seasonal variations. ${ }^{34}$

\section{DPPH Antioxidative Scavenging Activity}

1,1diphenyl 2- picryl hydrazine DPPH is a stable nitrogen containing free radical at room temperature which gives deep purple colour when dissolved in ethanol/methanol. The method is based on measurement of the percentage inhibition of DPPH by the plant extracts and upon reduction it changes colour from deep purple to yellow due to formation of diamagnetic molecule. The degree of discoloration is indicative of the antioxidative activity of tested samples with the decrease in absorbance with increase in the concentration of extracts. This in vitro method is widely used for the estimation of primary antioxidant activity. ${ }^{43,44}$ The DPPH inhibition was at site 1 and site 2 was $69.21 \pm 0.80$; and $84.23 \pm 0.70$ (stage I); $51.21 \pm 0.93$ and $69.31 \pm 0.53$ percent at site 1 and 2 respectively. Finally, at stage III the inhibition was 61.35 \pm 1.3 percent and $69.46 \pm 0.41$ (stage III) (Figure 3A). In DPPH assay, the percentage inhibition activity in vegetative, pre-flowering and post flowering stage increased from site 1 to site 2 by $21 \%, 35.3 \%$ and $13.2 \%$ respectively. However, the vegetative stage, at site 1 showed increment of $11.36 \%$ and $17.54 \%$ at site 2 in comparison to post flowering stage. However, comparing the vegetative stage with pre-flowering stage there was decline in activity was $26.01 \%$ at site 1 and $17.71 \%$ site 2 . It was observed that scavenging activity was higher at site 2 than site 1 and the percentage inhibition showed the following trend Stage I > Stage III $>$ Stage II. This outcome is also supported by Nyonje, $(2014)^{38}$ who also reported that Stage II showed least percentage inhibition. The values for DPPH scavenging percentage in our study was similar to Enujiugha (2014) who reported 74-90\% inhibition in case of ethanolic extract. It is clear from our results that altitudinal variation (Site 1-site2) has an impact on antioxidant activity. Besides the seasonal and temperature variation might have profound effect upon antioxidant activity of plant extracts. These conclusions are supported by Iqbal and Bhanger, $(2006) .^{34}$

\section{Superoxide Radical (SOD) scavenging activity}

In superoxide dismutase (SOD), superoxide anions are generated through PMS-Riboflavin coupling system followed by reduction with nitro blue tetrazolium (NBT). The decrease in absorbance with the increase in concentration of extract indicates consumption of the superoxide anions in the reaction mixture. Superoxide dismutase scavenging activity at site 1 and site 2 was $64.59 \pm 0.80$ percent and $73.14 \pm 0.31$ stage I; $53.60 \pm .92$ and $61.35 \pm 3.43$ percent and $70.55 \pm 1.5$ at site 1 and 73.08 \pm 0.22 percent stage III respectively( Figure $3 \mathrm{~B}$ ). The SOD percentage inhibition activity increased from site 1 to site 2 by $13.24 \%, 20.68 \%$ and $3.59 \%$ at stages I-III. The SOD activity decreased at pre-flowering stage by $17 \%$ at site I and $11.56 \%$ at site 2 but it increased at post flowering stage by $9.22 \%$ and $0.08 \%$ at site 1 and site 2 in comparison to vegetative stage. Superoxide anions result in the formation of more reactive species like hydrogen peroxide, hydroxyl radical, and singlet oxygen, which in turn damage lipids, proteins, and DNA. Therefore, studying the scavenging activity of plant extracts on superoxide radical is one of the most important ways of clarifying the mechanism of antioxidant activity. The results regarding the superoxide radical scavenging activity by various extracts of Amaranthus caudatus revealed that site 1 exhibited less inhibition of superoxide anions compared to site 2 . It was also observed that maximum percentage inhibition was attained at stage I and lowest at stage II. The trend observed was similar to the earlier two assays specifying that SOD inhibition activity is also affected by agroclimatic zonation and seasonal variation.

\section{Hydrogen Peroxide $\left(\mathrm{H}_{2} \mathrm{O}_{2}\right)$ radical scavenging activity}

$\mathrm{H}_{2} \mathrm{O}_{2}$ is converted into $\mathrm{H}_{2} \mathrm{O}$ and $\mathrm{O}_{2}$ in the body which might produce free radicals like hydroxyl radical that ultimately causes lipid peroxidation and DNA damage. In this assay the ability of different extracts is tested to scavenge this hydrogen peroxide. An stage I the hydrogen peroxide percentage inhibition at site 1 and site 2 was $81.29 \pm 1.56$ and 88.99 \pm .035 percent stage I; $78.72 \pm 4.45$ and $89.03 \pm 1.08$ percent stage II and $80.38 \pm 1.29$ and $91.14 \% \pm 0.95$ at site 1 and 2 respectively (Figure $3 \mathrm{C}$ ). The percentage inhibition increased at vegetative, pre-flowering and post flowering stages from $9 \%, 13 \%, 13.4 \%$ from site 1 to site 2 respectively. Hydrogen peroxide is an intermediate compound during endogenous oxidative metabolism which results in the formation of more highly reactive hydroxyl radical through the Fenton reaction. Highly reactive hydroxyl radicals are responsible for the oxidative damage of DNA, lipids and proteins. It was also that the increase in the altitude (site 1-site2) led to an increase in the antioxidant activities. The $\mathrm{H}_{2} \mathrm{O}_{2}$ scavenging activity was high at stage I but decreased at stage II and then showed again increase at the stage III at both sites. Here also seasonal influence was apparent from results as the less activity was observed in warm season 


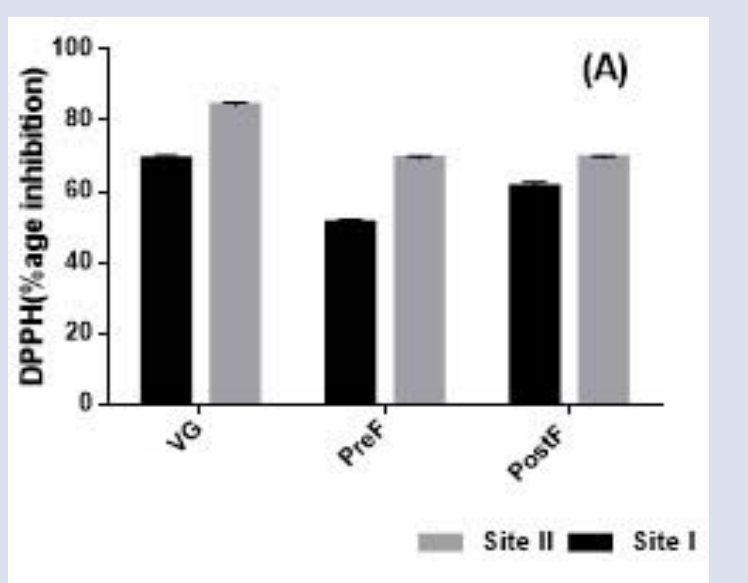

(B)
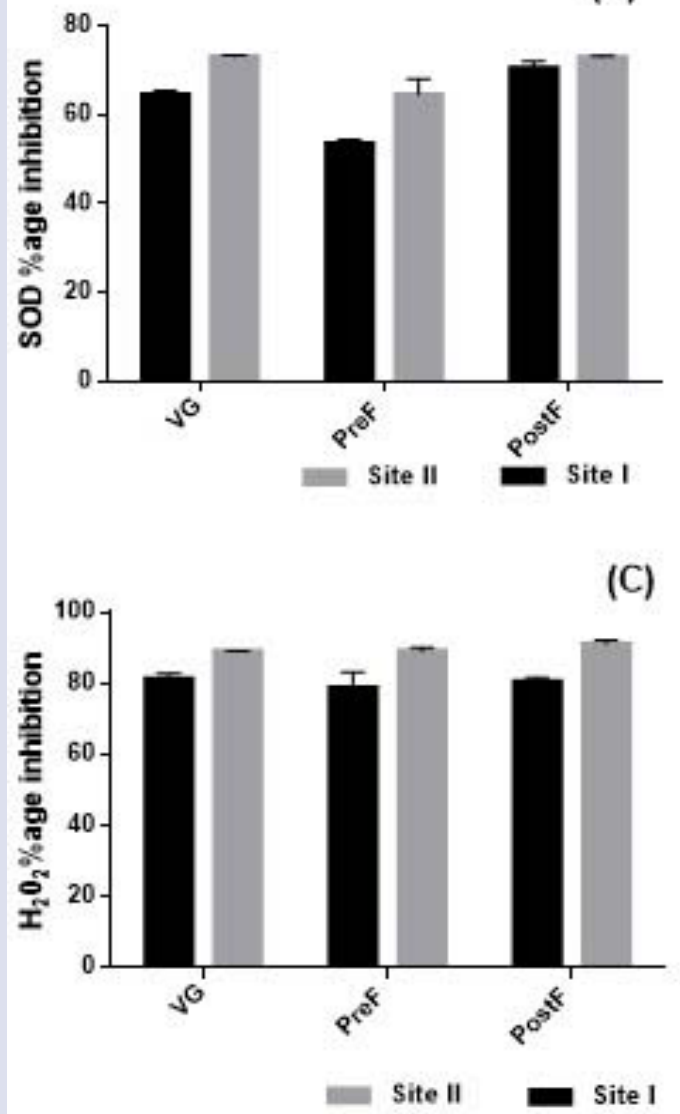

Figure 3: DPPH (A); SOD (B) and $\mathrm{H}_{2} \mathrm{O}_{2}$ percentage inhibition (C) in ethanolic leaf extract of Amaranthus caudatus L. grown at two different sites.

(stage II) at both the sites and satisfactory results were obtained during moderate temperature of the year (stage I and III).

The $\mathrm{IC}_{50}$ values for SOD, $\mathrm{H}_{2} \mathrm{O}_{2}$ and DPPH were calculated (Table 1). The table clearly depicts that the less concentration of leaf extracts belonging to site 2 is needed to get $\mathrm{IC}_{50}$ values.

\section{CONCLUSION}

The Amaranthus caudatus L. was grown at different sites and the leaves from three developmental stages were assessed for antioxidant assays. It was noticed that the plants grown at higher altitude provided better results for antioxidative activity as well for total phenols and flavonoids. At both
Table 1: $\mathrm{IC}_{50}$ values of ethanolic extracts of leaf material at different altitudinal sites in three different stages.

\begin{tabular}{lllllll} 
& DPPH & \multicolumn{3}{c}{ SOD } & & $\mathrm{H}_{2} \mathrm{O}_{2}$ \\
& Site 1 & Site 2 & Site 1 & Site 2 & Site 1 & Site 2 \\
Stage 1 & 3.51 & 1.501 & 2.07 & 1.42 & 3.01 & 2.15 \\
Stage II & 4.832 & 2.92 & 3.91 & 3.00 & 2.37 & 1.56 \\
Stage III & 3.92 & 1.97 & 3.15 & 2.57 & 0.89 & 0.23
\end{tabular}

the sites, the lowest activity was observed at stage II, which means the seasonal variation plays an important role. Further the results revealed that because of natural free radical quenching activity of Amaranthus caudatus, it can be utilized as a promising plant product for ROS associated diseases. The large scale cultivation of this crop especially at high altitudes is having a promising potential because in these areas there are climatic constrains for the cultivation of the conventional crops.

\section{ACKNOWLEDGEMENT}

RUR is thankful of University of Kashmir for providing the Seed Grant.

\section{CONFLICT OF INTEREST}

The authors declare that there is no conflict of interest with any party.

\section{ABBREVIATIONS}

ROS: reactive oxygen species; EtOH: ethanolic extract; FRAP: Ferrous reducing antioxidative power; DPPH: diphenyl picryl hydrazine; SOD: superoxide dismutase; $\mathrm{H}_{2} \mathrm{O}_{2}$ : hydrogen peroxide; TPTZ: 2, 4, 6-tri-pyridyl-s-triazine; $\mathrm{FeCl}_{3}$ : Ferric chloride; Pre F: preflowering; Post F: post flowering; VEG: vegetative stage

\section{REFERENCES}

1. Apel K, Hirt H. Reactive oxygen species: metabolism, oxidative stress, and signal transduction. Annual Review Plant Biology. 2004;2(55):373-99.

2. Del Rio LA, Sandalio LM, Corpas FJ, Palssma JM, Barroso JB. Reactive oxygen species and reactive nitrogen species in peroxisomes. Production, scavenging, and role in cell signaling. Plant Physiology. 2006;141:330-5.

3. Halliwell B. Oxidative stress in cell culture: an under?appreciated problem? Federation of European Biochemical Socities letters.2003;540(1-3):3-6.

4. Pezzuto JM, Park EJ. Autoxidation and antioxidants. In: Swarbrick, J., Boylan, J.C. (Eds.), Encyclopedia of Pharmaceuticals Technology, vol. 1, second ed. Marcel Dekker Inc., New York. 2002;97-113.

5. Razali I, Norhaya H, Norasimah AS. Determination of antioxidants in Palm Oil products by HPLC. Elaeis. 1997;9(1):25-31.

6. Ames BN, Shigenga MK, Hagen TM. Oxidants, antioxidants and degenerative diseases of aging. Proceedings of the National Academy of Sciences of the United States of America. 1993;90:7915-22.

7. Halliwell B. Ascorbic acid in the prevention and treatment of cancer. Alternative Medicine Reviews. 1996;3(3):174-86.

8. Edge R, McGreevy DJ, Truscott TG. The carotenoids as antioxidants: A review. Journal of Photochemistry and Photobiology B. Biology. 1997;41:189-200.

9. Zhang HY, Wang LF. Theoretical elucidation on structure- antioxidant activity relationships for indolinonichydroxylamines. Bioorganic and Medicinal Chemistry Letters. 2002;12(2):225-7.

10. Argolo ACC, Sant'Ana AEG, Pletsch, Coelho LCBB. Antioxidant activity of leaf extracts from Bauhinia monandra. Bioresource Technology. 2004;95(2):229-33.

11. Krishnaiah $D$, Sarbatly $R$, Nithyanandam $R$. A review of the antioxidant potential of medicinal plant species. Food and Bioproducts Processing. 2011;89(3):21733.

12. Mlakar, Turinek, Jakop, Bavec, Bavec. Grain amaranth as an alternative and perspective crop in temperate climate. Journal for Geography. 2010;5(1):135-45.

13. Barba RAP, Fomsgaard IS, Larsen B, Mortensen AG, Olvera-Mart?nez L, SilvaSanchez C, et al. Amaranth (Amaranthus hypochondriacus) as an alternative crop for sustainable food production: Phenolic acids and flavonoids with potential impact on its nutraceutical quality. Journal of Cereal Science. 2009;49:11721.

14. Kumar ABS, Lakshman K, Arun KPA, Viswanth GL, Veerapur VP, Thipeswamy BS. Hepatoprotective activity of methanol extract of Amaranthus caudatus $L$. 
against paracetamol-induced hepatic injury in rats. Chinese Journal of Integrative Medicines. 2010a;9(2):194-200.

15. Kumar ABS, Lakshman K, Jayaveera KN, Ranganayakulu D, Manoj B. Comparative in vitro anthelmintic activity of three plants belongs to Amaranthaceae. Archives of Biological Science. 2010b;62(1):185-9.

16. Kumar ABS, Lakshman K, Jayaveera KN, Sheshadri SD, Velmurugan C. Antinociceptive and Antipyretic activities of methanolic extract of Amaranthus caudatus L. Latin American Journal of Pharmacy. 2010c;29(4):1-5.

17. Kumar ABS, Lakshman K, Saleemullakhan, Velmurugan C, Vishwanath ER, Gopisetty MS. Evaluation of antidepressant like activity in Amaranthus caudatus L. Journal of Pharmaceutical Sciences. 2015;42(1):23-8

18. Girija K, Lakshman K. Anti-hyperlipidemic activity of methanol extracts of three plants of Amaranthus in triton-WR 1339 induced hyperlipidemic rats. Asian Pacific Journal of Tropical Biomedicine. 2011;S62-S5.

19. Andrea YA, Plate, José AG. Areas Cholesterol-lowering effect of extruded amaranth (Amaranthus caudatus L.) in hypercholesterolemic rabbits. Food Chemistry. 2002;76(1):1-6

20. Quershi AA, Lehman JW, Peterson DM. Amaranth and its oil inhibit cholesterol biosynthesis in 6-week old female chicken. Journal of Nutrion. 1996;126(8):19728.

21. Liu W, Yin D, Li N, Hou X, Wang D, Li D, Liu J. Influence of Environmental Factors on the Active Substance Production and Antioxidant Activity in Potentilla fruticosa L. and Its Quality Assessment.2016; Scientific Reports,6.

22. Do T, Nhuan, Eun-Sun H. "Bioactive Compound Contents and Antioxidant Activity in Aronia (Aroniamelanocarpa) Leaves Collected at Different Growth Stages."Preventive Nutrition and Food Science. 2014;19(3):204-12.

23. Malik EP, Singh MB. Plant Enzymology and Hittoenzymology ( $1^{\text {st }}$ Edn.) Kalyani Publishers: 1980; New Delhi; 286

24. Woisky R, Salatino A. Analysis of propolis some parameters and procedures for chemical quality control. Journal of Apicultural Research. 1998;37(2):99-105

25. Yen GC, Duh PD. Antioxidative properties of methanolic extracts from peanut hulls. Journal of American Oil Chemist's Society. 1993;70(4):383-6.

26. Benzie IFF, Strain JJ. The Ferric Reducing Ability of Plasma (FRAP) as a measure of "Antioxidant Power": The FRAP Assay.Analytical Biochemistry. 1996;239(1):70-6.

27. Moon JH, Terao J. Antioxidant activity of caffeic acid and dihydrocaffeic acid in lard and human low density protein. Journal of Agricultural and Food Chemistry. 1998;46(12):5062-5

28. Beauchamp C, Fridovich I. Superoxide dismutase: Improved assays and an assay applicable to acrylamide gels. Analytical Biochemistry. 1971;44(1):276-87.

29. Ebrahimzadeh MA, Seyed MN, Seyed FN, Fatemeh B, Ahmad RB. Antioxidant and Free Radical Scavenging Activity OF H. officinalis L. V. odorata, B. hyrcanaand C. speciosum. Pakistan Journal of Pharmaceutical Science. 2010;23(1):29-34.

30. Jung YS, Park JY, Ko SO, Kim YH. Stabilization of hydrogen peroxide using pthalic acids in the Fenton and Fenton like oxidation. Chemosphere. 2013;90(2):812-9.

31. Enujiugha VN, Oluwole TF, Talabi, JY, Okunlola Al. Selected Bioactive Components in Fluted Pumpkin (Telfairia occidentalis) and Amaranth (Amaranthus caudatus) Leaves.American Journal of Experimental Agriculture.2014;4(9):996.

32. Julkunen TR. Phenolic constituents of Salix: a chemotaxonomic survey of further Finnish species. Phytochemistry. 1989;25:663-7.

33. Wiermann R. 1981. Secondary plant products and cell and tissue differentiation In: Stumpf, P.K., Conn, E.E. (Eds.), The Biochemistry of Plants, vol. 7. Academic Press Inc., New York, pp. 85-116.

34. Iqbal S, Bhanger MI. Effect of season and production location on antioxidant activity of Moringaoleifera leaves grown in Pakistan. Journal of Food Composition and Analysis. 2006;19:544-51

35. Miller AL. Antioxidant Flavonoids: Structure, Function and Clinical Usage. Alter native Medicine Revive. 1996;1(2):103-11.

36. Bors W, Heller W, Michel C, Saran M. Flavonoids as antioxidants: determination of radical-scavenging efficiencies. Methods in Enzymology. 1990;186:343.

37. Akubugwo IE, Obasi NA, Chinyere GC, Ugbogu AE. Mineral and phytochemical contents in leaves of Amaranthus hybridus Land Solanum nigrum L. subjected to different processing methods. African Journal of Biochemistry Research. 2008:2(2):40-4.

38. Nyonje WA, Makokha AO, Abukutsa-Onyango MO. Anti-Nutrient, Phytochemical and Antiradical Evaluation of 10 Amaranth (Amaranthus spp.) Varieties Before and After Flowering. Journal of Agricultural Science.2014;6(4):68.

39. Olajire AA, Azeez L. Total antioxidant activity, phenolic, flavonoid and ascorbic acid contents of Nigerian vegetables. African Journal of Food Science and Technology. 2011;2(2):22-9.

40. Nabavi SM, Ebrahimzadeh MA, Nabavi SF, Fazelian M, Eslami B. In vitro antioxidant and free radical scavenging activity of Diospyros lotus and Pyrus boissieriana growing in Iran. Pharmacognosy Magazine. 2009;4(18):123-7.

41. Oktay M, Gulcin I, Kufre VOI. Determination of in vitro antioxidant activity of fennel (Feoniculum vulgare) seed extracts. Lebanon Wissen Technology. 2003;36:263-71.

42. Cirak C, Radusiene J, Camas N, Caliskan O, Odabas MS. Changes in the contents of main secondary metabolites in two Turkish Hypericum species during plant development. Pharmaceutical Biology. 2013;51(3):391-9.

43. Brand-Williams W, Cuvelier ME, Berset C. Use of free radical method to evaluate antioxidant activity. Lebanon Wissen Technology. 1995;28(1):25-30.

44. Katalinic V, Milos M, Modun D, Music I, Boban M. Antioxidant effectiveness of selected wines in comparison with (+) - calectin. Food Chemistry. 2004;86:593600.

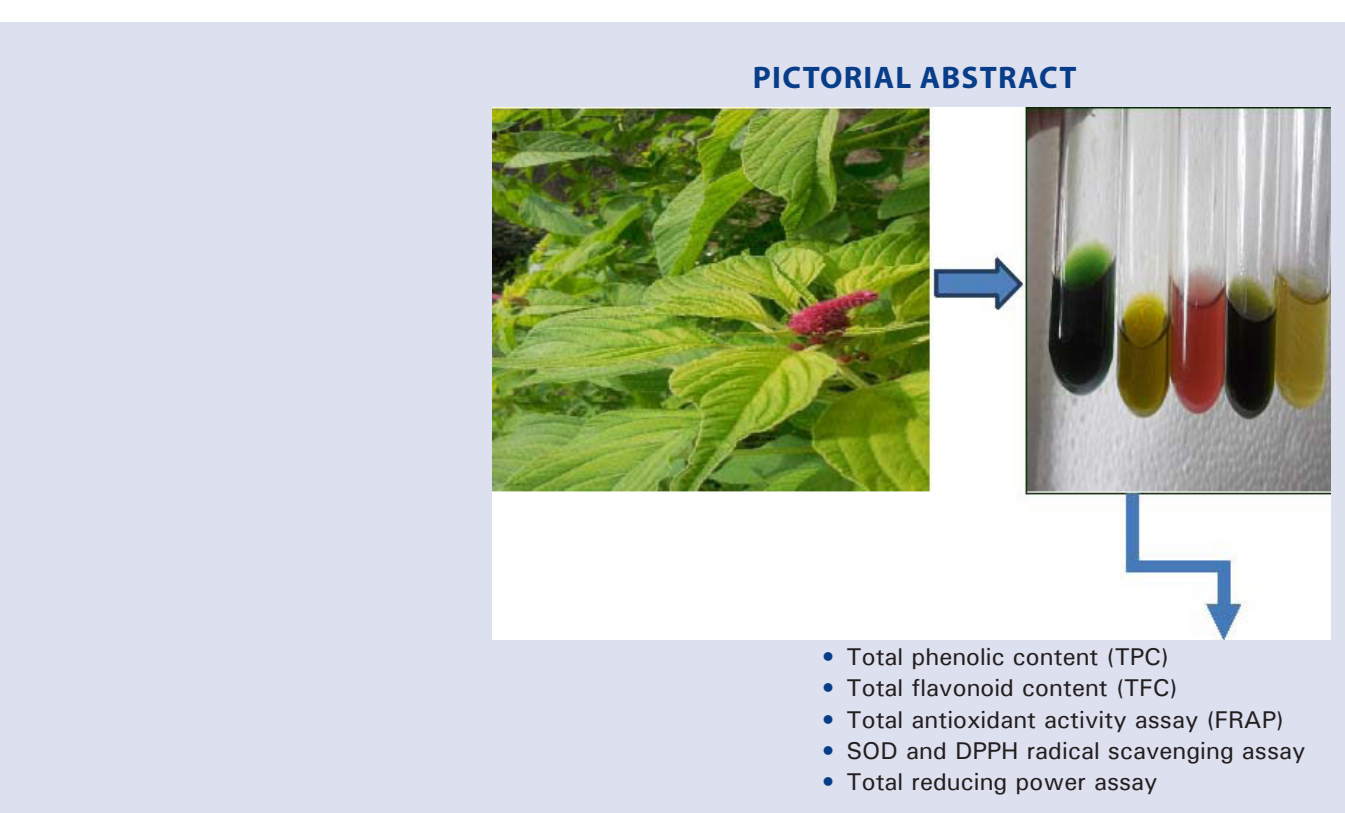

Cite this article: Asiya R, Inayatullah T, Reiaz UR. Evaluation of in vitro Antioxidant Potential of Amaranthus caudatus L. Grown in Kashmir Region Pharmacog J. 2018;10(6):1119-24 